\title{
Bridging the Gap between University Curriculum and Industrial Needs: A Case Study of Teaching Interpersonal Skills
}

\author{
Savina Manevska*, Kwasi Asare Baffour Danquah, Cleland Fiifi Afful, Jana \\ Smerdova, Nedelcho Manev \\ Czech College
}

\begin{abstract}
Keywords:

Interpersonal skills,

Negotiation skills,

Effective communication

skills, Leadership skills,

Training and development

\section{Received}

20 October 2017

Received in revised form 01 May 2018

Accepted

21 May 2018

Effective interpersonal skills represent a major success factor in almost every aspect of the business world today. To have a competitive advantage, new graduates must master those skills with limited or even non-existing experience - an area where most business schools face severe breach between their curriculum and company expectations. This article looks at bridging the interpersonal skill gap through the implementation of relevant internship experience for students. Some of the skills been looked at are negotiation skills, effective communication skills, leadership skills, training and development. The approach incorporates collaborated final assessment of student knowledge and skills from both educational institution and business entity. The result of the research aims at creating an objective tool of assessment criteria for evaluating the adaptivity of interpersonal skills, acquired by students in their Business Administration Program.
\end{abstract}

Correspondence:

savina@czco.cz

Due to current trends, the work place is becoming more of a virtual rather than the usual physical one. But there are certain aspects that would always remain the same. There is the need for universities and colleges to takes steps to adequately prepare their graduates for industry. Graduates from universities and colleges have to understand the dynamism in most 
work places as they have become quite diverse. Therefore, this requires that products (graduates) from both colleges and universities understand the need to effectively interact with their colleagues to impact efficiency as well as integrate into their specific roles. It is necessary for specific social skills to be enhanced and harnessed for the proper and effective delivering of one's responsibilities. This is where interpersonal skills become necessary as we consider their association with others in the social sphere (Hardina, 2013). Many stakeholders have suggested different approaches in dealing with this growing gap. Some have tried to use Research and Development (R\&D), collaborative projects, and internships as a way of bridging the gap between universities, colleges and industry (Larkin, 2014).

\section{Interpersonal skills}

According to Hayes (2003), interpersonal skills are defined as 'one of a number of broadly similar terms that are sometimes used interchangeably. Other such terms include interactive skills, people skills, face-to-face skills, social skills and social competence'. For one's competence vis a vis interpersonal skills, it depends on the ability to understand and deal with the social interaction dynamics (Hayes, 2003). Mostly this focuses on dealing with inherently rational as well as process orientation (Duffy, Gordon, Whelan, Cole-Kelly, \& Frankel, 2004). These skills may include negotiation, effective communication, leadership, and training and development skills. These sets of skills are necessary for one's ability to gain employment, be productive and also be successful in the chosen career (Johnson \& Johnson, 1989; Robles, 2012). It must be noted that at times interpersonal skills and soft skills have been used interchangeably, but they are not the same (Hardina, 2013). Interpersonal skills are a subset of soft skills which mostly refer to the character traits that one relies on in relating to others.

\section{Gap between University Curriculum and Industry}

University education is said to be universal education. But over the years a gradual gap has occurred which has, in some cases, made graduates less prepared for industry. The necessary skill sets needed specifically for industry are sometimes missing when students complete university and enter the workforce. There is not enough collaboration between academia and industry so as to prepare students adequately for industry as expected (Trauth, Farwell, \& Lee). In other words, the gap is being caused by the difference in expectations of industry and the academic preparations that graduates receive from universities. In a case study, Meredith and Buckle (2008) analyzed questionnaires and found that bridging the gap between universities and industry brings about full learning and it is no longer just about theories but also having industrial experience (Meredith \& Burkle, 2008). This equips graduates to properly fit into industry.

\section{Method \\ Interviews}

The best place for us to find the shortcomings of most of university and college products is in the field. Therefore, extensive interviews were conducted to really assess if there was an issue regarding interpersonal skills of graduates. Along with one managing director, managers of different departments within 7 companies were interviewed. The interview 
questions were structured in a way to allow theses managers to answer questions concerning interpersonal skills of new graduates from universities and colleges. Each manager was given room to outline the various interpersonal skills that they look out for within their respective departments. The way managers assessed their subordinates on interpersonal skills was also studied.

\section{Administering Questionnaires}

Questionnaires were administered based on 5 multi-choice questions centered on specific areas of interpersonal skills. These questions were structured to get a better view of how these different mangers were assessing their employees. The questionnaire examined some of the interpersonal skills that managers deem new graduates they employ struggle with. This gave us an industry perspective of specific interpersonal skills that new graduates from colleges and university may lack. Another area we sought to answer was how new graduates with some internship experience performed as compared to those without, from the various managers' experience. A different set of managers answered the questionnaires as compared to those involved in our interview sessions.

\section{Results and Discussion}

Managers strongly relate interpersonal skills with work performance especially for new graduates in the training period. Its successful completion depends on their ability to listen, understand and communicate. Problem solving seems to be an essential ability for team leaders as well. In this study, we realized this as one of the key interpersonal skill that managers looked for (Figure 1 and 2). One of them explained it this way “...I've given them a number of tasks which I've reviewed and can see their tone is that which is required for support. They've shown logic in problem solving and taken an end user approach to support." New employees often find themselves in stressful situations in the first couple of months on a new position. Managers claim it is as a result of "little or no experience, they most often lack problem solving skills and are unable to stay focused under pressure. “ 


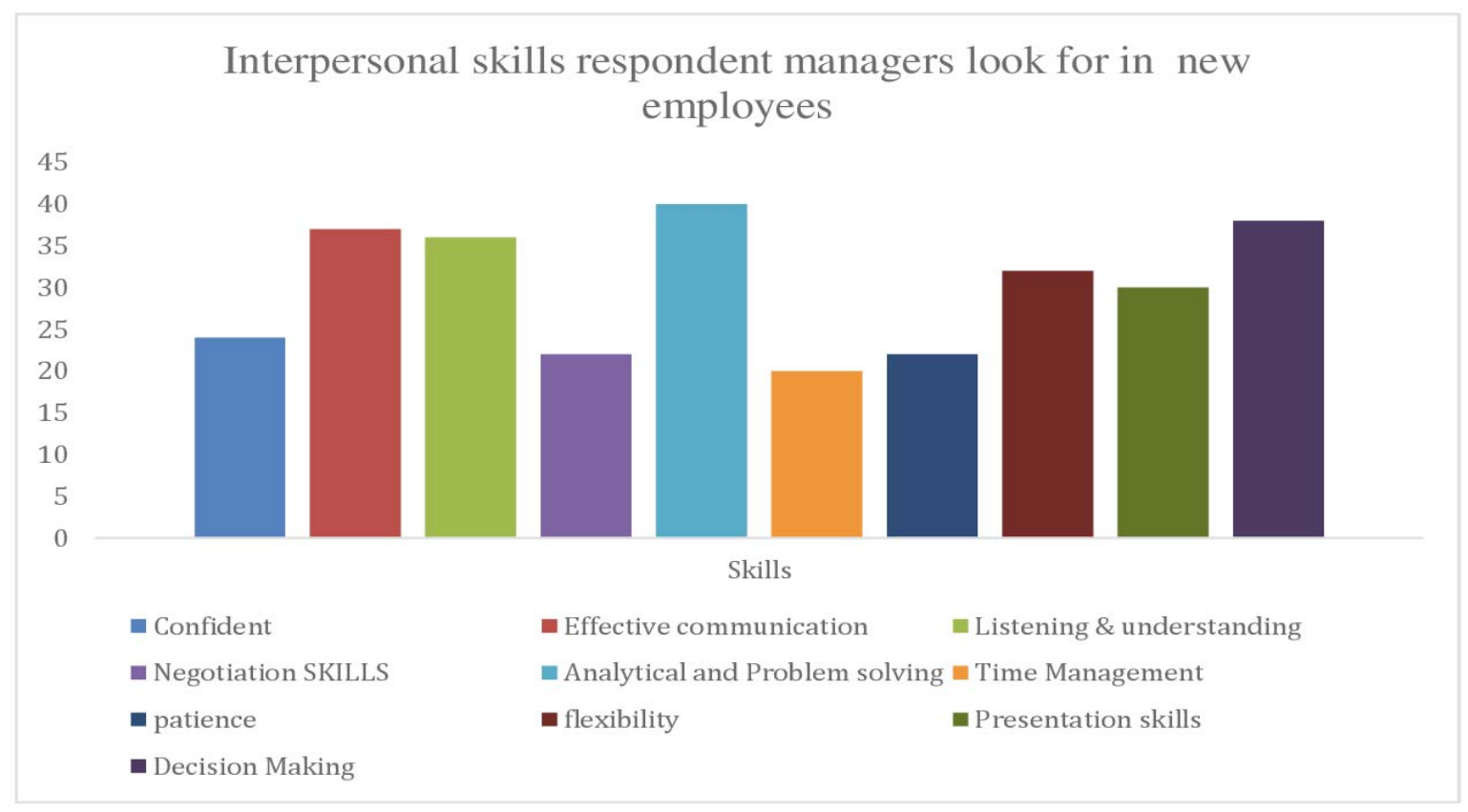

Figure 1. Interpersonal skills managers look for in new employees (Interview Results)

Making decisions and being confident are other abilities desired by employers; this can be seen from the response from managers (Figure 1 and 2). Managers showed little confusion and misunderstanding of the origin of those decisions. Fresh graduates might be able to demonstrate confidence as an interpersonal skill though most decision in this initial stage requires specific knowledge that they might be lacking.

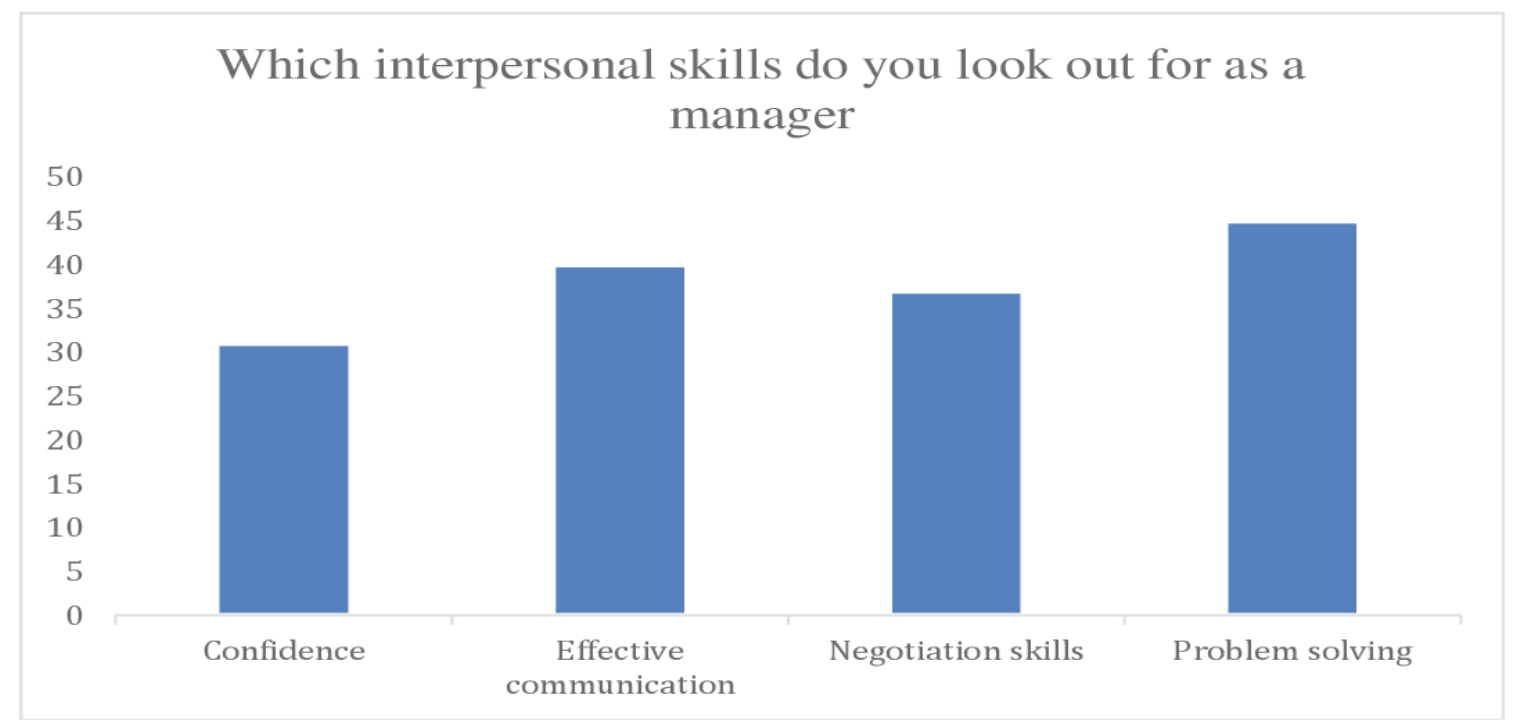

Figure 2. Interpersonal skills that managers interviewed look out for

The requirements referring to interpersonal skills that could be found in the job specifications of researched companies include both proactive and self-focused abilities. The business envisions fulfilled individuals who were able to effectively manage themselves while performing their tasks. When those ideal expectations meet the reality of new graduates, the collision is inevitable. Interviewed managers shared that in many instances frustration from both employee and employer sides accompany everyday work. This is 
partially due to unrealistic requirement levels, ineffective initial assessment and educational gaps.

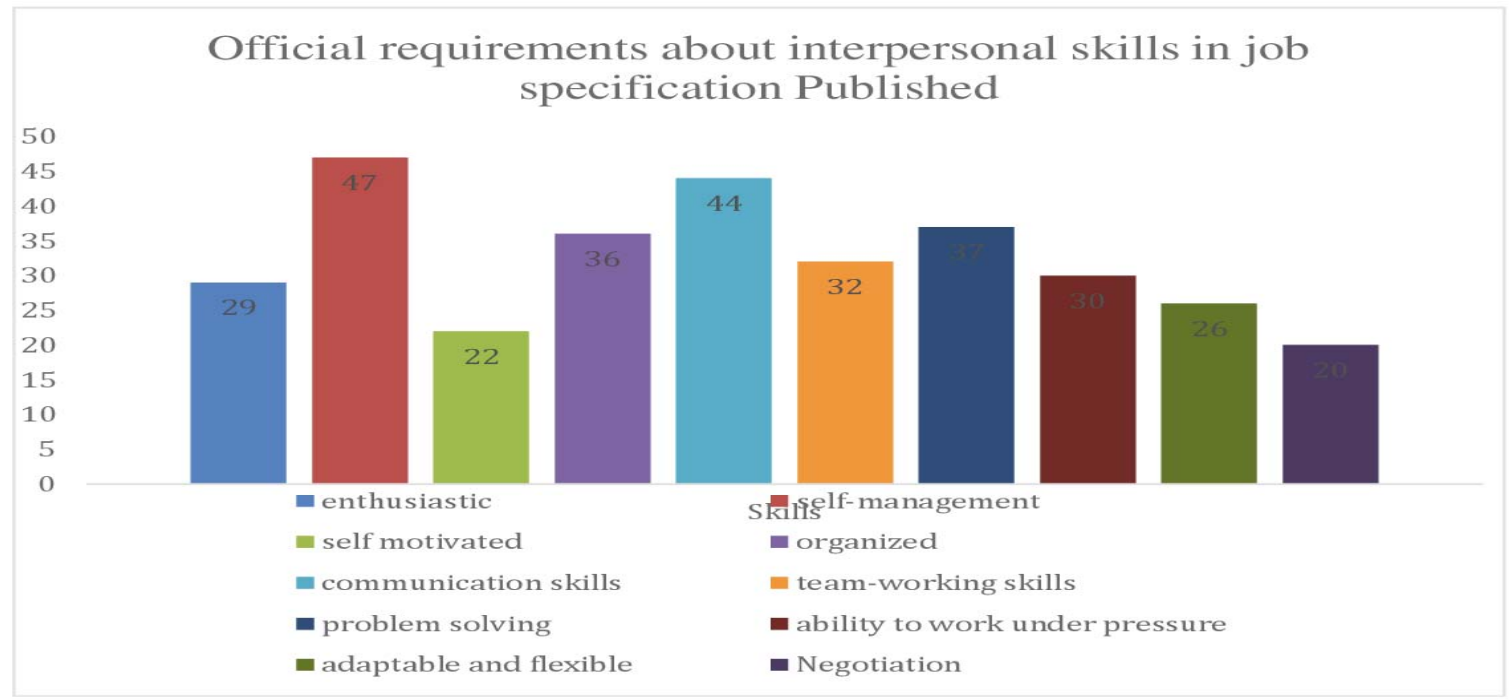

Figure 3. Interpersonal skills in official job specification (Interview Results)

When comparing company interpersonal skills requirements and manager individual expectations (Figure 1 and 3), an interesting phenomenon is observed. Team leaders tend to be more practical, accentuating proactively in interpersonal skills. They strongly consider the training period (which in some of the researched companies could be up to 6 months) as a learning process. Communication, listening and understanding are essential during this time for fresh graduates to live up to the standards.

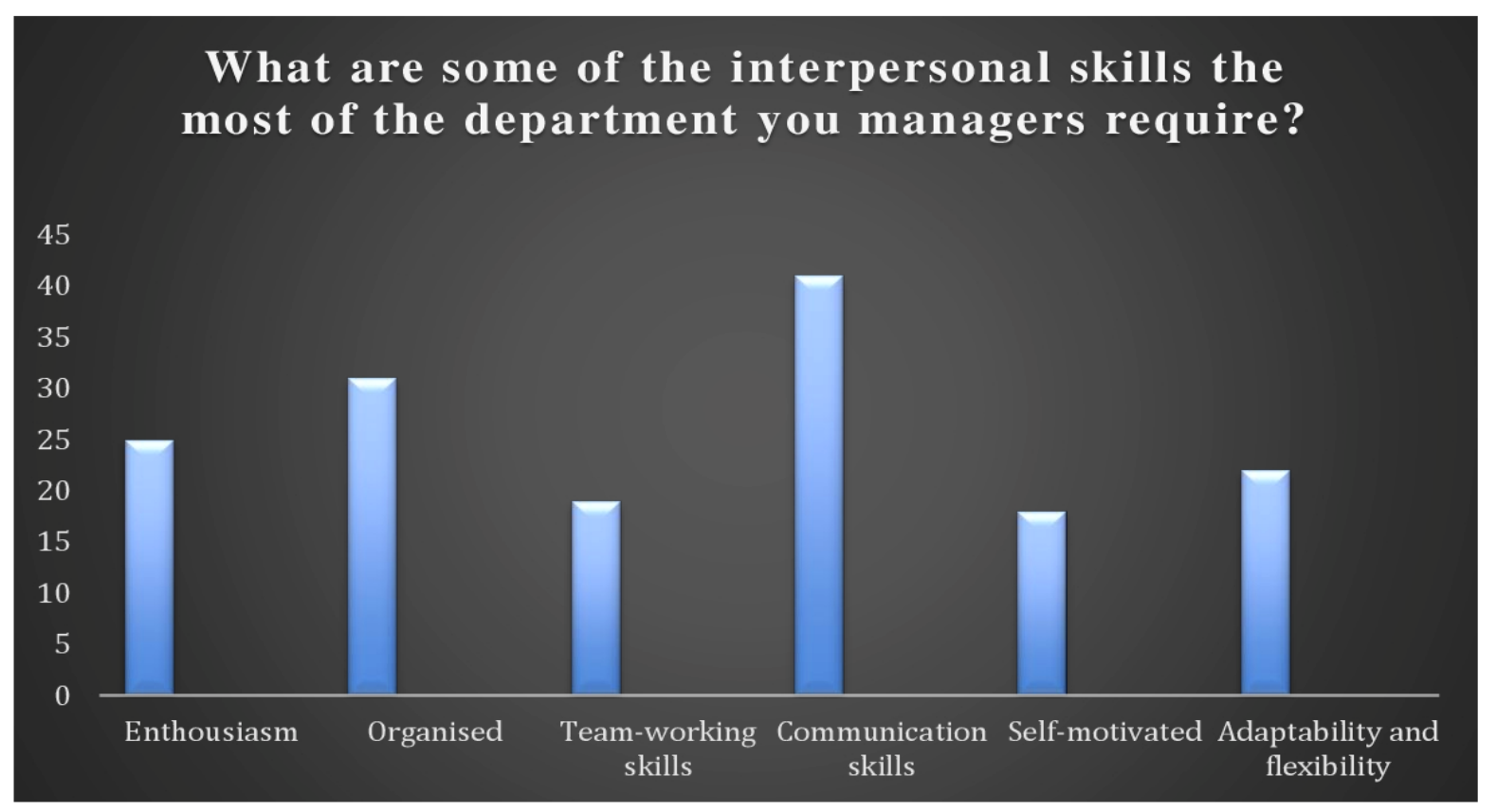

Figure 4. Department requirements of interpersonal skills (Questionnaire Results) 


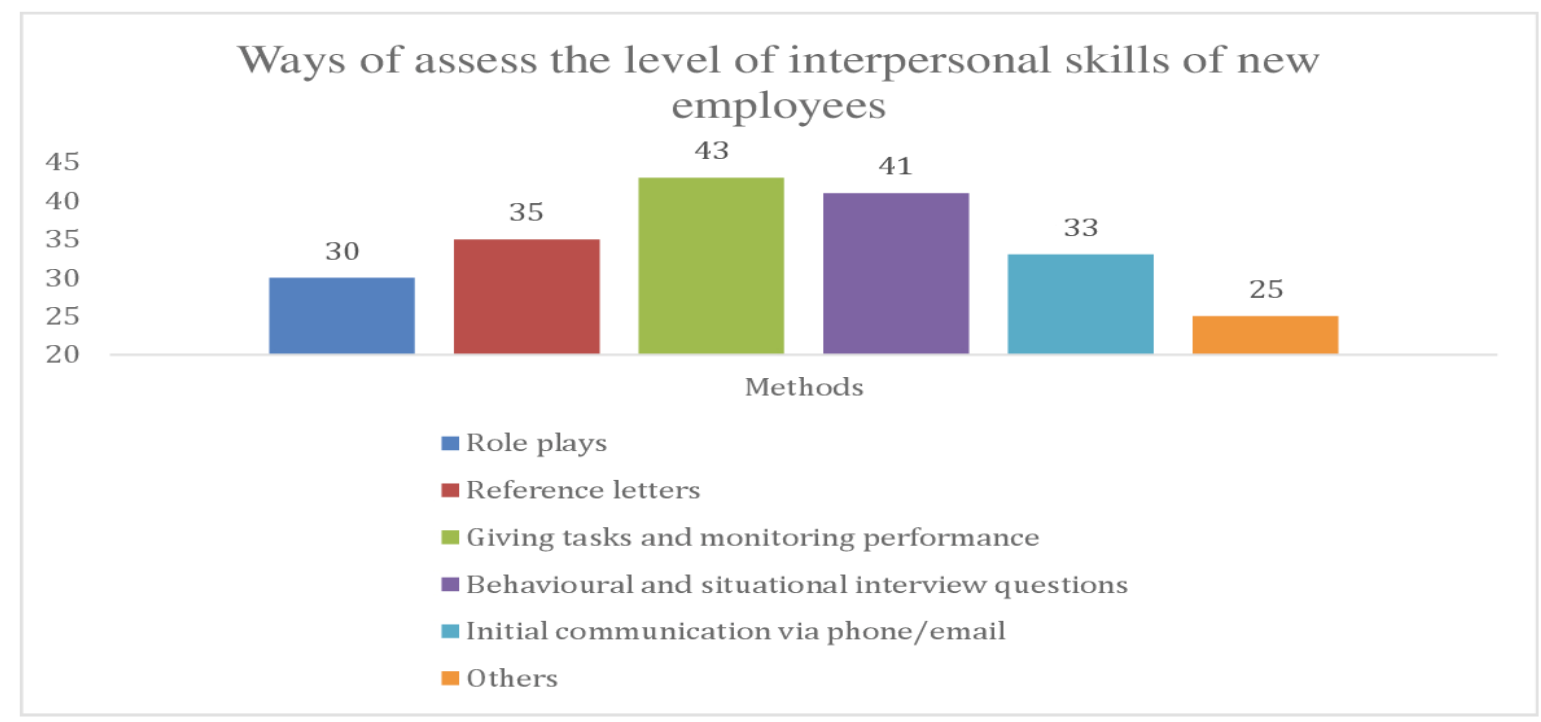

Figure 5. Assessment of interpersonal skill (Interview Results)

The assessment of interpersonal skills is a process that most managers find difficult. They suggest various strategies but when discussing effectiveness, refer mostly to monitoring performance and face-to-face interviews. Both approaches showed results which could be maximized when combined. Thus, managers' engagement interferes on a passive and active level revealing a detailed picture of new employees' abilities and knowledge.

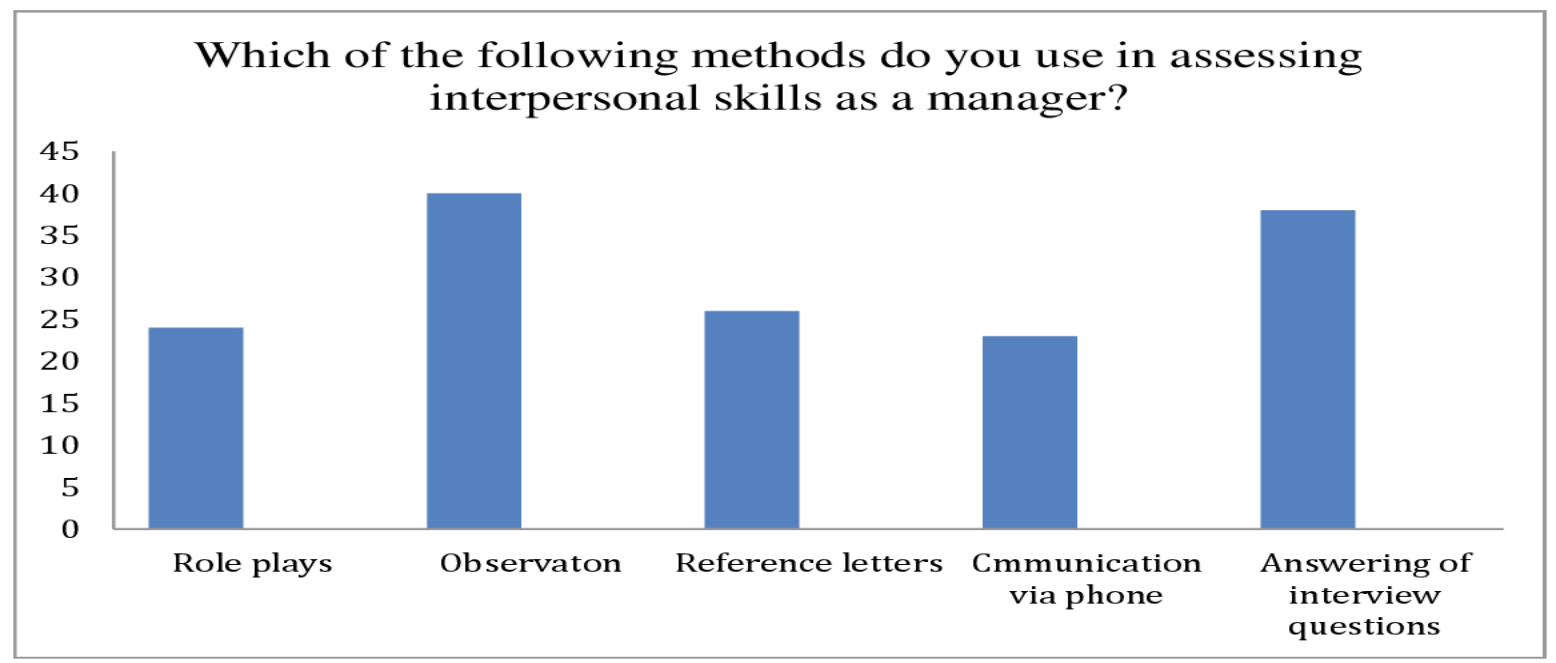

Figure 6. Methods of interpersonal skill assessment (Questionnaire Results)

Even though both tools are useful, team leaders applied them without using a particular structure. Tasks and situational questions varied with no evidences of implementing a logical pattern. Managers relied on their experience and inner feeling to determine the best approach of assessment. 


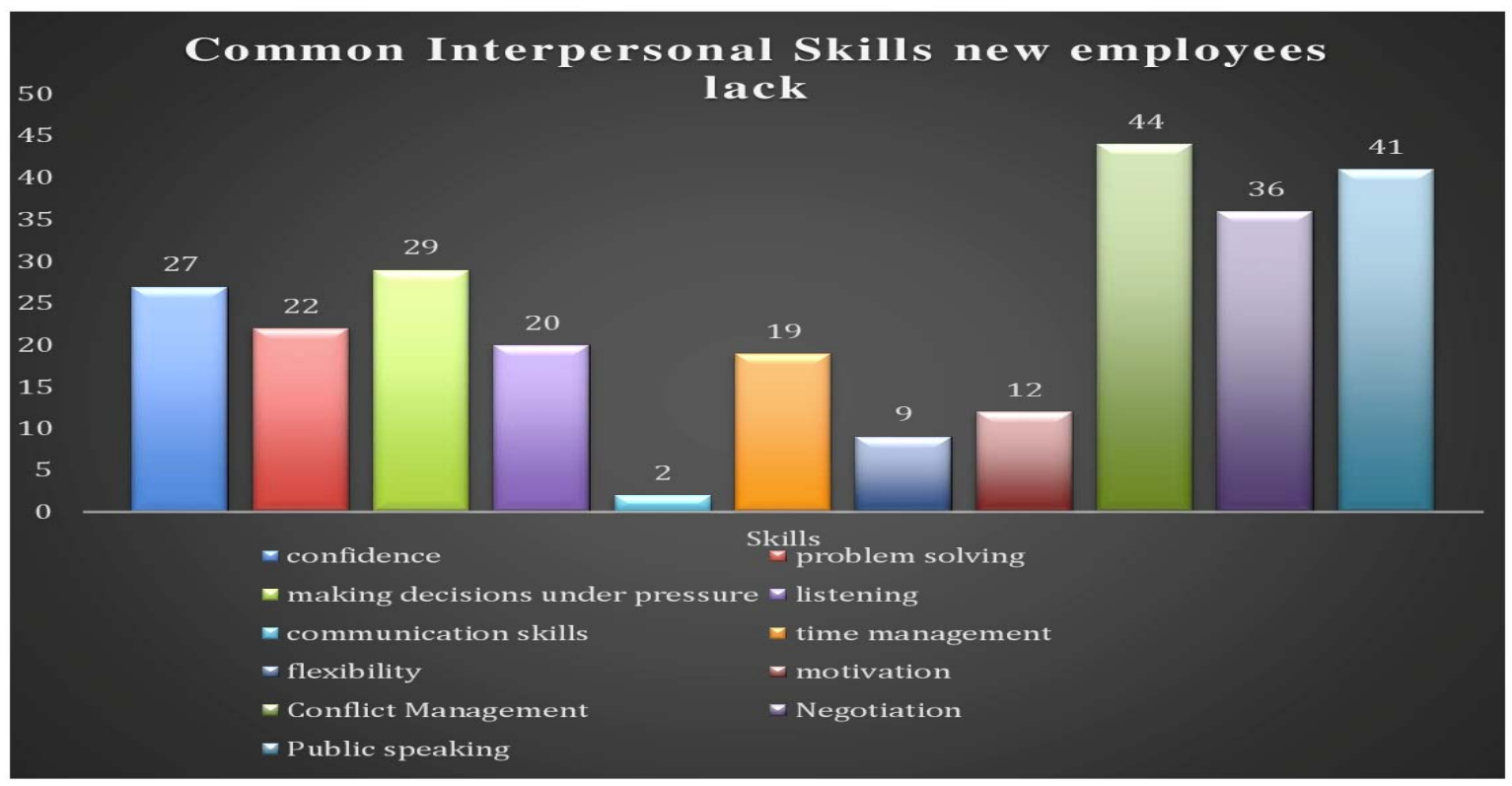

Figure 7. Common interpersonal skills new employees lack (Interview Results)

After performance and evaluation, managers determined the current ability levels of their new team members. The questionnaire results (Figure 8) clearly indicated that the interpersonal skills that new graduates struggle with are mostly making decisions under pressure and confidence. These skills were closely related to each other, demonstrating insufficient classroom experience in case study simulations and debates. During the interviews, managers listed several additional interpersonal skills that new graduates were lacking including flexibility, communication, skills, etc.

As shown in Figure 8, conflict management, negotiation skills and public speaking are those that stood out the most. Academic experience only tends to provide limited opportunities for development of more specialized interpersonal skills. Fresh graduates managed to adapt well in their teams, communicate with their colleagues and complete their tasks within certain deadlines but when it comes to relatively typical work situations involving higher levels of stress, new employees failed to confidently apply their knowledge into practice.

Team leaders mentioned internships as a successful approach to overcome the skill gaps described above. All 50 interviewees claimed that new graduates with some internship experience are better prepared for the position they apply for. Their level of confidence, selfmanagement and effectiveness are higher compared to new employees without any practice. One of the interviewees stated, "The new employees whom have attended an internship are more confident in the communication between colleagues and clients. They are familiar with most of the problems that may arise during the working process and they know how to react accordingly." The results revealed that fresh graduates with internship experience make quality decisions under pressure - one of the most sensitive areas when discussing interpersonal skill gaps. 


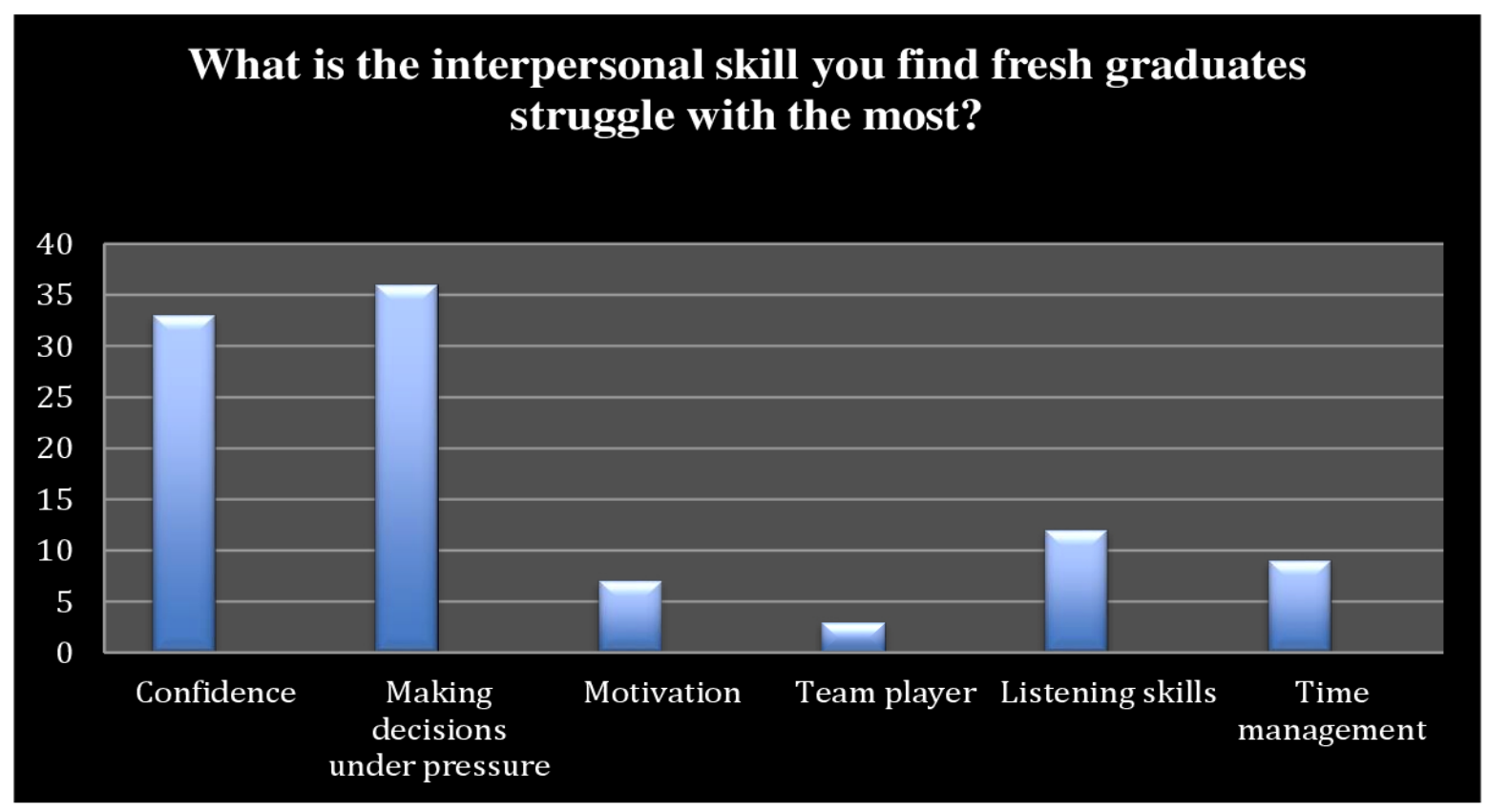

Figure 8. Interpersonal skills fresh graduates struggle the most with (Questionnaire Results)

Managers considered internships to be a critical factor of the educational experience of students especially when it comes to interpersonal skills. The interview analysis demonstrated an interesting observation - there were different sets of skills academia and business developed even if both find vast implication in career development. Business looks at interpersonal skills from a practical perspective - interaction, adaptability and confidence stimulate performance, while universities still use an approach of delivering knowledge mainly listening, communication skills and time management.

\section{Implications and Suggestions about Future Research}

The gap between academia and industry in the context of interpersonal skills has been caused by the inability of academia to collaborate with industry to understand their needs so that the production line of graduates will reflect these needs. This study revealed several directions where efforts must be directed.

Firstly, there must be acceptance that the gap exists and that there is the need for the existing gap to be bridged between industry and university curriculum. This gap often leads to the unemployability of graduates after school and sometimes leads to graduates doing jobs that they are far overqualified for because they lack the prerequisite skills to make it into qualified positions. Secondly, internships should be used during the study period to better equip and prepare graduates for industry. Internships are preparation grounds for new graduates. It is where skills and theories learnt in school are tested since role playing in classroom setting does not really reflect reality, proper planning of internship and help graduate be ready for reality through dealing with real issues that have significant impacts on companies.

New graduates should be mentored on interpersonal skills. Interpersonal skills like effective communication, problem solving skills, negotiation, etc., go a long way to help slowly integrate new graduates into the business world by making them interact better and 
understand the whole organizational behavior. Mentoring involves having an experience that guides a graduate by advising, sharing knowledge and opening-up about the way of improving for the graduate. This can be done by managers and supervisors during coordinated internships.

Internships should come with a form of assessment tool that is created with the collaboration of the managers of the industry the graduate is going to and the academic institution the graduate is from. The use of assessment tool during the internship helps give feedback as well as bring a sense of awareness to the graduate about where they lack certain skill and what to improve. This in turn gives a potential employer what to focus on in developing the graduate. Universities can also use this to help the graduate improve the skills they lack through counseling.

Managers should also emphasize the relevance of interpersonal skills during on boarding of new employees (fresh Grads) and so should the academic environment. This two-prang approach will help instill the basic skills in the graduate before they finally venture into the real business world.

Continuous research on the collaboration between industry and Universities should be conducted, especially in the field of the assessment. This will then contribute to the solution of the dialogue regarding the unemployability of some graduates.

\section{References}

Duffy, F. D., Gordon, G. H., Whelan, G., Cole-Kelly, K., \& Frankel, R. (2004). Assessing competence in communication and interpersonal skills: The Kalamazoo II report. Academic Medicine, 79(6), 495-507.

Hardina, D. (2013). Interpersonal social work skills for community practice. New York: Springer Pub.

Hayes, J. (2003). Interpersonal skills at work (2nd ed). New York: Routledge, Hove.

Johnson, D. W., \& Johnson, R. T. (1989). Cooperation and competition: Theory and research. Edina, MN, US: Interaction Book Company.

Larkin, M., 2014. Building successful partnerships between academia and industry. Elsevierconnect. Retreived from https://www.elsevier.com/connect/building-successful-partnerships-between-academia-and-industry

Meredith, S., \& Burkle, M. (2008). Building bridges between university and industry: Theory and practice. Education Training, 50, 199-215.

Robles, M. M. (2012). Executive perceptions of the top 10 soft skills needed in today's workplace. Business Communication Quarterly, 75(4), 453-465.

Trauth, E. M., Farwell, D. W., Lee, D. (1993). The IS expectation gap: Industry expectations versus academic preparation. Mis Quarterly, 293-307. 